\title{
نظام النقحرة من اللغة العربية إلى اللغة الإندونيسية
}

\author{
Ade Destri Deviana*
}

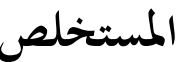

إن اللغة لما خصائص تتميّز باللغة الأخرى كانت في مجال النطق وصوةا، أو في قواعد كتابتها أو غيرها. و وهي علامة ورموز . وعندما تُكتب أو تُحوّل إلى اللغة الأخر ى في فكانت مسائل المنظورة من من اللغة الأصلية لأهما (اللغة الأصلية واللغة الأخرى) تفريقان في النطق، والصوت، والتركيب، والجمل. خصوصا في الإندونيسيا. أن الإندونيسيا يستخدم اللغة الإندونيسية التي بالحروف اللاتينية. وهو بلاد التي يسكن المسلمون والمسلمين. عادة، ويحتاجون عن العلوم الإسلامية تكتب باللغة العربية بالحروف الهجائية. هذه الصعبة لهم • إذن يجتاج تحويل اللغة العربية إلى اللغة الإندونيسية أو الحروف الهجائية إلى الحروف اللاتينية. وهي تسمى بالنقحرة (transliteration).

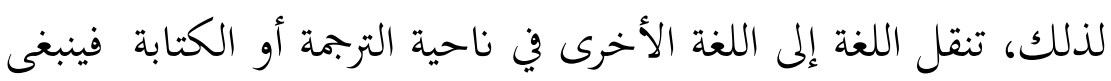
لما النظام المعيّن واللازم لعملية النقل والتحويل من مراعاة المعنى المتوى في اللغة المنقولة (اللغة الأصلية) لسهلة فهمها وتعريف عن نطقها.

*Penulis adalah dosen Sekolah Tinggi Ilmu AlQuran (STIQ) Amuntai Kalimantan Selatan. Dan sedang melanjutkan Studi S3 di SPs UIN Maulana Malik Iberahim Malang

Jurnal Ilmiah Al QALAM, Vol. 9, No. 17, Januari-Juni 2016 
في الإندونيسيا، النقحرة هي إحدى المشكلات في الكتابة. كانت

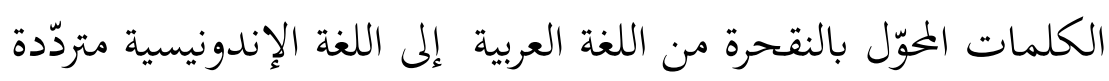

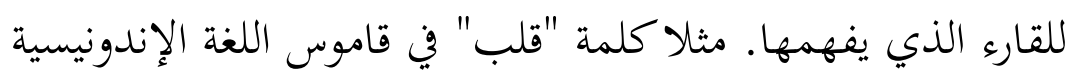

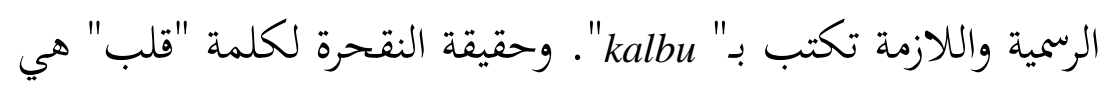

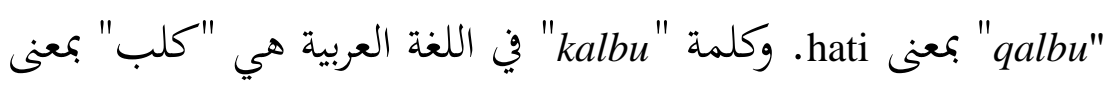

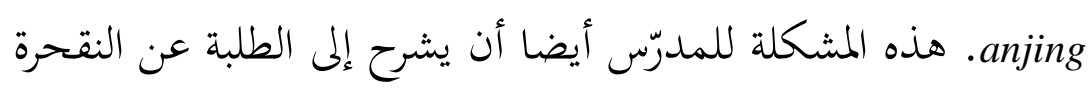

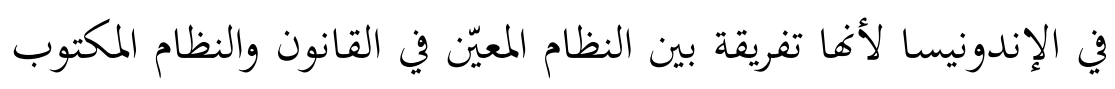
في قاموس اللغة الإندونيسية (KBBI).

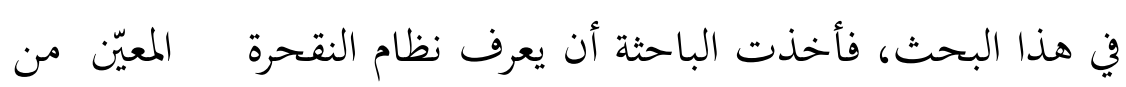

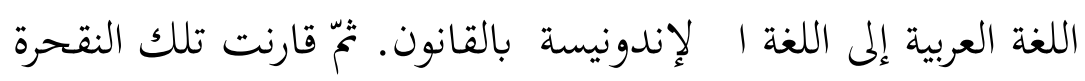

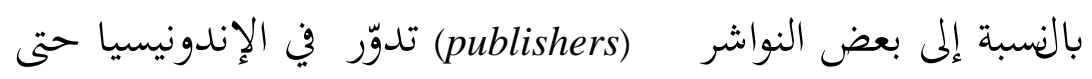
تكتشف الباحثة عن نظام النقحرة في الإندونيسا. في عملية البحث، أن الباحثة تستطيع أن تعرف أن نظام النقام النحرة هي

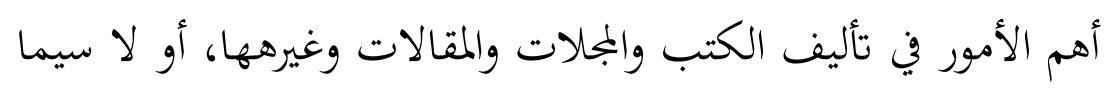

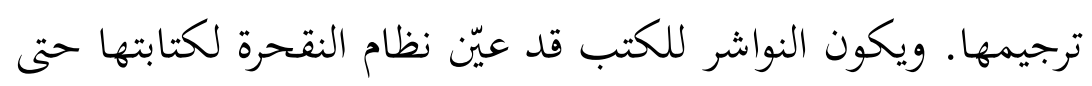

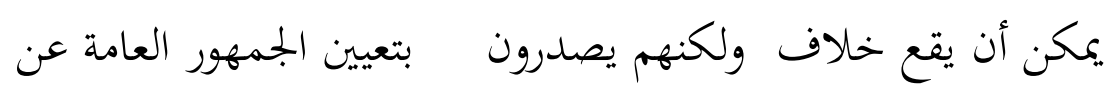

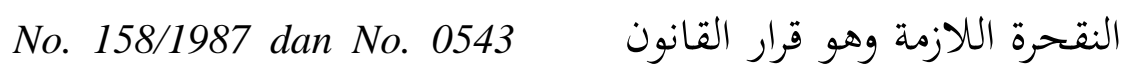
$. b / U / 1987$

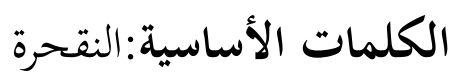




\section{أ. النقحرة من اللغة العربية إلى اللغة اللاتينية}

\section{1}

من اللغويون النقحرة تشابه بالكتابة (transkription) في نحاية

المعنى. وهي تحويل الكتابة من اللغة الواحدة إلى اللغة الأخرى.

وحقيقة، أن المصطلحين سواء. لا فرق بينهما. قد نأخذ تعريفهما فيما

أ - النقحرة هي كتبة اللغة بحروف اللغة الأخرى تستخدم رموزا

هجائية مختلفة. 1' وقال قريش شهاب: إن النقحرة هي عمل

لتنقيل الحروف للّغة الواحدة إلى اللغة الأخرى. 2مثل: "رسول

الله"- في اللغة العربية- وتكتب بـ " Rasulullah" - في اللغة

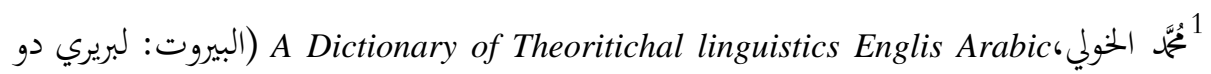

$$
\text { ليبان، 2008)، ص. } 289
$$

2 أمام مسلمين ، كتابة ونقحرة 201ul Albab: Jurnal Studi Islam sains dan Teknologi

$$
356 \text {.2006،vol.7 No.2 }
$$

Jurnal Ilmiah Al QALAM, Vol. 9, No. 17, Januari-Juni 2016 
الإندونيسية-، و "قلب"-في اللغة العربية- تكتب بـ "qolbu"

$$
\text { في اللغة الإندونيسية-. }
$$

ب - الكتابة هي التعبير عن اللغة المنطوقة برموز كتابة مناسبة بالنطق

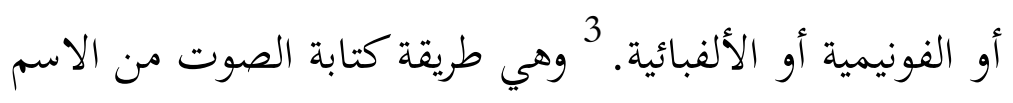

أو الكلمة بالحروف الأبجدية الأصلية إلى الأبجدية الأخرى،

ومثل: "عُحَّه" - - في اللغة العربية- تكتب بـ"Muhammad" أو

$$
\text { "Muhamad" }
$$

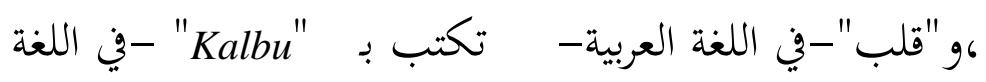

$$
\begin{aligned}
& \text { الإندونيسية- أو "ميانمار"بالحروف الهجائية تكتب بـ } \\
& \text { "Myanmar" }
\end{aligned}
$$

\footnotetext{
3 289

4لويس معلوف اليسوعي، المزبد في اللغ والأعلام (بيروت: دار المشرق، 2008)، ص. 567
}

Jurnal Ilmiah Al QALAM, Vol. 9, No. 17, Januari-Juni 2016 
وقرّرت الباحثة المتّبعة من ذلك الشرح أن النقحر والكتابة فرق

بينهما من كتابهما (لو قد يتساويان في الكتابة)وتعريفهما ولكن

تشابهان ومناسبان ومتعلّقان إلى ناحية المعنى.

2

من ذلك التعريف السابق فتهدف النقحرة مما يلي:

أ. تعبير المفردات من اللغة العربية إلى اللغة الإندونيسية بالحرف

اللاتينية حتى يسهل الأشخاص للتلفظها.

ب. يستطيع أن يقرء القارء مفردات جيّدا وصحيحا لأنه يعتمد بنظام

النقحرة المعينة حتى لا يقع الأخطاء كثيرا في التلفظ وفهم معانى

$$
\text { المفردات الأصلية من اللغة العربية. }
$$

ج. تسهيل الكاتبين والمترجمين غير الناطقين لأن يكتبوا المفردات من الحروف الهجائية باللغة العربية إلى الحروف اللاتينية باللغة

$$
\text { الإندونيسية. }
$$

Jurnal Ilmiah Al QALAM, Vol. 9, No. 17, Januari-Juni 2016 


\section{3}

إن في النقحرة، المفردات هي لا متساوية تعريف في المعنى أو لا

رموز لها في اللغة الأخرى أي في هذا البحث لم تكن الحروف الهجائية

تتساوي بالحروف اللاتينية. في نظام النقحرة نستطيع أن نكتب تلك

المفردات بالعلامات المميزة وهي علامة فوق الحروف أو تحته لتدلّ

على سمة إضافة لها بوضع علامة واحدا لفونيم واحد. مثل: "خاء"

تكتب بـ kha)، و "ثاء" تكتب بـ

أو zh.

وفي العملية للنقحرة، يخلّف كثير من الكاتبين عن نظام النقحرة

حتى يأتي المجتمع العامة مفقة عن النقحرة من اللغة العربية إلى اللغة

الإندونيسية بأن يجعل القانون لنظام النقحرة اللازمة أي قرار الوزراء

رقم No. 158/1987 dan No. 0543 b/U/1987.

وتضمّنت القانون عن النقحة إلى عشرة : الصامت

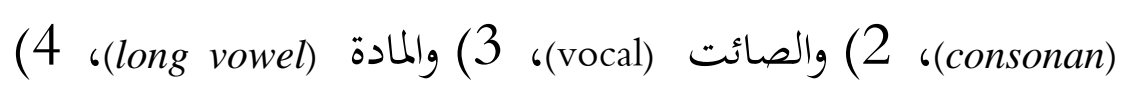

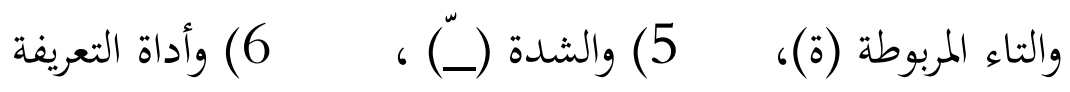

Jurnal Ilmiah Al QALAM, Vol. 9, No. 17, Januari-Juni 2016 
أدي ديستري ديفيانا: نظام النقحرة من اللغة العربية إلى اللغة الإندونيسية

9 ( ) ، (definitearticle)

والحروف الكبيرة (cavital letter)، 10) وبتويد. 5

وهذا الشرح عن ما سابق فيما يالي:

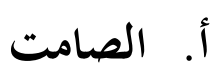

الصامت في نظام اللغة العربية يرمز بالحرف. وفي

نام النقحرة يرمز بالحرف و العلامة.

\begin{tabular}{|c|c|c|c|}
\hline الشرح & اللاتينية & التلفظ باللاتينية & الهجائية \\
\hline دون علامة & - & Alif & 1 \\
\hline- & $B$ & $B a$ & ب \\
\hline- & $T$ & $T a$ & ت \\
\hline فنقطة واحدة & $\dot{s}$ & $\dot{s} a$ & ث \\
\hline- & $J$ & Jim & ج \\
\hline h بنقطة واحدة & $h$ & ha & $\tau$ \\
\hline
\end{tabular}

${ }^{5}$ A. Bahruddin, Malik dkk, Pedoman Transliterasi Arab Latin(Jakarta: Badan Litbang Agama dan Diklat Keagamaan proyek Pengkajian dan Pengembangan Lejtur pendidikan Agama, 2003, p. 3)

Jurnal Ilmiah Al QALAM, Vol. 9, No. 17, Januari-Juni 2016 
أدي ديستري ديفيانا: نظام النقحرة من اللغة العربية إلى اللغة الإندونيسية

\begin{tabular}{|c|c|c|c|}
\hline تحته & & & \\
\hline- & $K h$ & Kha & $\dot{\tau}$ \\
\hline- & $D$ & Dal & 2 \\
\hline فنبطة واحدة & $\dot{Z}$ & $\dot{Z} a l$ & $\dot{j}$ \\
\hline- & $R$ & $R a$ & J \\
\hline- & $Z$ & Zai & j \\
\hline- & $S$ & $\operatorname{Sin}$ & س \\
\hline- & Sy & Syin & ش ش \\
\hline s بنقطة واحدة & $\underline{S}$ & șad & ص \\
\hline $\begin{array}{l}\text { واحدة تحته d بنقة } \\
\text { واحتة }\end{array}$ & $d$ & dad & ض \\
\hline تحته t بنقة واحدة & $t$ & ta & b \\
\hline تجته z بنقة واحدة & $z$ & $z a$ & ظ \\
\hline المقلوب & ' & ain & c \\
\hline- & $S$ & Gain & $\dot{\varepsilon}$ \\
\hline
\end{tabular}

Jurnal Ilmiah Al QALAM, Vol. 9, No. 17, Januari-Juni 2016 
أدي ديستري ديفيانا: نظام النقحرة من اللغة العربية إلى اللغة الإندونيسية

\begin{tabular}{|c|c|c|c|}
\hline- & $F$ & $F a$ & ف \\
\hline- & $Q$ & Qaf & ق \\
\hline- & $K$ & Kaf & ك \\
\hline- & $L$ & Lam & J \\
\hline- & $M$ & Mim & b \\
\hline- & $N$ & Nun & ن ن \\
\hline- & $H$ & $\mathrm{Ha}$ & هـ \\
\hline- & $W$ & Wau & 9 \\
\hline 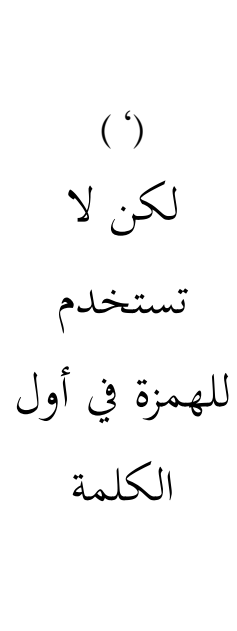 & تكون & Hamzah & $s$ \\
\hline - & $Y$ & $Y a$ & \\
\hline
\end{tabular}

فالصائت هي اثنان وهما الصائت البسيط

(dhiptong) الصائت (monophtong)

Jurnal Ilmiah Al QALAM, Vol. 9, No. 17, Januari-Juni 2016 
البسيط هو الحركة أي صائت لا تغيير نوعيته من بداية

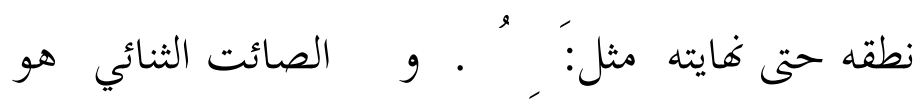

تخليط من الصامت والحركة مثل : كَيْ ، لوّ . وهذه نظام

النقحرة للصائت البسيط والصائت الثنائي هما يسخدمان

بالحروف.

\begin{tabular}{|c|c|c|}
\hline العلامة في اللجائية & التلفظ في اللاتينية \\
\hline$A$ & Fathah & - \\
\hline$I$ & Kasrah & - \\
\hline$U$ & Dammah & - \\
\hline$A u$ & Fathah dan wau & $\vdots . .$. \\
\hline$A i$ & Fathah dan ya & \multirow{2}{*}{} \\
\hline
\end{tabular}

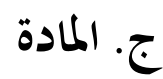

المادة هو الصائت الطويل الذي يرمز بالحرف

يعتمد فترة نطقة أي : a : u ومن آراء اللغويون برموز

Jurnal Ilmiah Al QALAM, Vol. 9, No. 17, Januari-Juni 2016 
الصوت الطويلة أي ، ،a ، ،ii ورموز الصائت القصيرة

فقد أي a، i، u، ورموز الحرف بالعلامة واحدة فوقه أي أ،

مثل:كلمة "قال" تكتب وحاصل

$$
\text { مفقة في القانون هو بـأ، }
$$

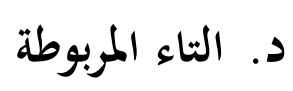

أن نظام النقحرة في كتابة التاء المربوطة نوعان وهما

الأولى بt عندما كانت التاء المربوطة بالفتحة أو الكسرة

أو الضمة (ةَةقِةُ) والثانية بـ h عندما كانت بالسكون (ةْ)

فأما لزم ب t لاسيما التاء المربوطة بالسكون وهي "زكة"

و "صلاة" تكتبان zakat و Salat. ومثل: "روضة الأطفال"

raudah al-atfal g raudatul atfal تكتب

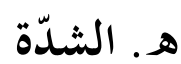

أن الشدة في النقحرة ترمز بكتابة الحرف زائد

يستوي بالحرف المشدّد. مثل: كلمة ربّنا" تكتب

.Rabbana

Jurnal Ilmiah Al QALAM, Vol. 9, No. 17, Januari-Juni 2016 


\section{و. أداة التعريفة}

أداة التعريفة وهي ال التعريفية لاسم المعرفة. ومن

$$
\text { رأي اللغويون ينقسم ال إلى قسمين:6 }
$$

1. ال التي تدخله الحروف الشمسية، فيحصل التماثل

والإدغام. وهذه تكتب بحسب الصوت. مثل "التّراب "

$$
\text { atturāb تكتب }
$$

2. ال التي تدخله الحروف القمرية فيحصل النطق أو

التفظ معها بالام (ال) أو هي التي لا تتحوّل لام (ال)

إليها لفظا إذا دخلت عليها. مثل: كلمة " البقرة"

$$
\text { al-Baqarah تكتب }
$$

$$
\text { ز. - م الممزة }
$$

قد عرف أن الهمزة المتوسطة والمتطرفة بعلامة ( ")

والهمزة الابتدائية دون العلامة، وهذه كتابة النقحرة سواء

$$
\text { umirtu بالألف. مثل: كلمة "أُمرْتُ " تكتب }
$$

6 ناصف يامين ،المعتم المغصل في الإملاء قواعد ونصوص (بيروت: دار المكتبة العلمية ،1992)، 


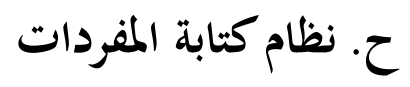

أن نظام كتابة المفردات مطابقة بالنظام السابق في

الاسم، والفعل، والحرف. وهو قسمان في كتابة النقحرة.

وهي تكتب برموز الحروف والعلامات التي تتصل بين

الكالمتين أو أكثر، وتكتب برموز الحروف والعلامات التي

تفرق بين الكالمتين أو أكثر. مثل: " ل

والميزان" تكتب بـ fa aufūl-kaila wal-mizāna

aufū al-kaila wa-almizāna

\section{ط. الحروف الكبيرة}

لا يوجد الحرف الكبير في نظام كتابة اللغة العربية.

ولكن إذا ينقل في كتابة النقحرة باللغة الإندونيسة فيقوم

بالحرف الكبير في الحرف الابتدائية في أول الجملة، ويف

الاسم العلمية. مثل: "وما عُمَّمَ إلا رسول" تكتب بـ Wa

.Muhammadun illa rasul

Jurnal Ilmiah Al QALAM, Vol. 9, No. 17, Januari-Juni 2016 


\section{ي. تجويد}

التجويد هو مبادئ للقارء القرآن فصيحا

وصحيحا. وتضمّن على مخارج الحروف وصفاهما، وأحكام

قراءة الهجائية، والمد والقصر، والوقف. 7

\section{ب. المقارنة عن النقحرة للنواشر}

قبل أن تقارن الباحثة عن القحرة للنواشر، تحاول أن توزّع

مقارنة عن النقحرة والكتابة ولو آرى بعض اللغويين يتساوي

بينهما. هذه المقارنة لسهل فهم القارئ أو لسهل المدرّس أن

يشرحها إلى الطلبة.

أن القحرة هي عمل لتنقيل الحروف للّغة الواحدة إلى اللغة

الأخرى، وهنا للغة العربية إلى اللغة الإندونيسة بالنظام المعيّن اللازم

No. 158/1987 dan No. 0543 ميالقانون أي قرار الوزراء رقم

$. b / U / 1987$

7مُّمَّ، بصري علوي مرتضى،مبادئ على التجويد(مالانج: رحمتك. 2009)، ص.4

Jurnal Ilmiah Al QALAM, Vol. 9, No. 17, Januari-Juni 2016 
والكتابة هي عمل كتابة الصوت من الاسم أو الكلمة

بالحروف الأبجدية الأصلية إلى الأبجدية الأخرى، مناللغة المنطوقة

برموز كتابة مناسبة بالنطق أو الفونيمية أو الألفبائية التي تناسب

بالنطق للناطقين بغيرها في البلاد المعيّن، وكثيرا قد كتبت اللغة في

$$
\text { قاموس اللغة اللإندونيسية. }
$$

هذا جدول المقارنة عن النقحرة والكتابة باللغة الإندونيسية

\begin{tabular}{|c|c|c|c|}
\hline \multicolumn{2}{|c|}{ اللغة الأخرى باللغة الإندونيسية } & \multirow{2}{*}{ اللغة الأصلية } & \multirow{2}{*}{ 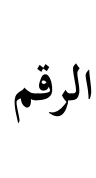 } \\
\hline الكتابة & النقحرة & & \\
\hline salat $^{8}$ & șalat & صلاة & 1 \\
\hline${ }^{9}$ kalbu & Qalbu & قلب & 2 \\
\hline${ }^{10}$ zuhur & zuhur & ظهور & 3 \\
\hline${ }^{11}$ ramadan & ramaḍan & رضان & 4 \\
\hline
\end{tabular}

${ }^{8}$ Tim Depdiknas, Kamus Besar Bahasa Indonesia Pusat Bahasa Edisi Keempat, (Jakarta: Gramedia Pusat Utama, P. 1208)

$$
10 \text { 10 } 1{ }^{1}{ }^{1}{ }^{1}
$$

Jurnal Ilmiah Al QALAM, Vol. 9, No. 17, Januari-Juni 2016 


$$
\begin{aligned}
& \text { أدي ديستري ديفيانا: نظام النقحرة من اللغة العربية إلى اللغة الإندونيسية } \\
& \text { قد قامت الباحثة أن تصف كتابة النقحرة من الناشرين } \\
& \text { بكتابينوهما: }
\end{aligned}
$$

Menyingkap tabir dua kalimat syahadat (perspektif .1

uin للأستاذة مملوئة الحسنة بناشsemantik tindak tutur)

$$
2008 \text { عام Malang Press }
$$

Pemikiran-pemikiran Teologi Dalam Sejarah .2

$$
\begin{aligned}
& \text { Pemikiran Islam للأستاذ حضريان شة أ. ب. } \\
& \text { بناشرAntasari Press عام } 2013
\end{aligned}
$$




\section{هذا جدول المقارنة عن النقحرة والكتابة من الناشرين}

\begin{tabular}{|c|c|c|c|c|c|c|c|c|}
\hline \multicolumn{2}{|c|}{ صفحة } & \multicolumn{2}{|c|}{ اللإندونيسية } & \multicolumn{2}{|c|}{ العربية } & \multirow{2}{*}{ الرمز } & \multirow{2}{*}{ النظام } & \multirow{2}{*}{ رقم } \\
\hline الكتاب (2) & الكتاب (1) & الكتاب (2) & الكتاب (1) & الكتاب (2) & الكتاب (1) & & & \\
\hline 23 & 182 & $\begin{array}{l}\text { Nadlariyyah } \\
\text { al-mafahim }^{14}\end{array}$ & lafzhil ${ }^{13}$ & المفاهيم & لفظي & ظ & الصامت & 1 \\
\hline \multirow[t]{2}{*}{68} & 95 & Shohihah & Al-Ushūl & صحيحة & الأصول & ص & & \\
\hline & 261 & Isti'arah & Shirāth & استعارة & صراط & ر & & \\
\hline 39 & 334 & al-qath'i & Shidq & القطع & صدق & ق & & \\
\hline 39 & 176 & Syahada & Nafsiyah & نفسية & شهد & 二 & الصائت & \\
\hline 39 & 183 & Bayan & Kalām & بيان & كلام & $1 二$ & المادة & \\
\hline
\end{tabular}

${ }^{13}$ Hadariansyah, Pemikiran pemikiran teologi Dalam Sejarah pemikiran Islam(Banjarmasin: Antasari press. 2013, P. 182)

${ }^{14}$ Mamluatul Hasanah, Menyingkap tabir dua kalimat syahadat(Malang: UIN Malang Press, 2008. P. 23) 
أدي ديستري ديفيانا: نظام النقحرة من اللغة العربية إلى اللغة الإندونيسية

\begin{tabular}{|c|c|c|c|c|c|c|c|}
\hline 39 & 177 & isti'arah & ma'nawiyyah & استعارة & معنوية & $\ddot{0}$ & المربوطة \\
\hline 39 & 307 & Bayyana & al-Sunnah & بيّن & السنّة & $\stackrel{\circ}{\circ}$ & الشدة \\
\hline 101 & 96 & Al-andad & Al-tauhid & الأنداد & التوحيد & ال ال & أتعريفة \\
\hline 29 & 45 & Iradiyah & Imamah & إرادية & إمامة & - & الهمزة \\
\hline 113 & 189 & $\begin{array}{c}\text { Mawadhi'u } \\
\text { al-julus }\end{array}$ & $\begin{array}{c}\text { Al-ibānah 'an } \\
\text { ushül al- } \\
\text { diyānah }\end{array}$ & موضع & أصول الدإبانة عن & - & كتابة \\
\hline 38 & 178 & al-Qur'an & al-Qur'an & القرآن & القرآن & - & الحروف \\
\hline
\end{tabular}

Jurnal Ilmiah Al QALAM, Vol. 9, No. 17, Januari-Juni 2016 


\section{ج. الحمة}

إن النقحرة هي عملية كتابة التي تنقل الحروف للّغة الواحدة إلى

اللغة الأخرى مثل من اللغة العربية إلى اللغة الإندونيسة أو من الحروف

الهجائية إلى الحروف اللاتينية. وتمدف النقحرة لتسهيل الفهم وتسهيل الأشخاص لكتابتها وتسهيل فهم المعنى من اللغة الأصلية جيّدا.

تستخدم النقحرة للتحاد سمة الكتابة عن الكاتبين والمترجمين، ولكن

يكاد منهم خلافا عن الكتابة عندما نألّف ونترجم الكتب. لو تخالف

No. بينهم ولقد حاول الجمهور العامة ليجعل النقحرة اللازمة بقرار القانون

$.158 / 1987$ dan No. 0543 b/U/1987

ولذلك، أن الباحثة تستطيع أن تعرف أن نظام النقحرة هي أهم

الأمور في تأليف الكتب والمجلات والمقالات وغيرهها، أو لا سيما

ترجيمها. ويكون النواشر للكتب قد عيّن نظام النقحرة لكتابتها حتى يمكن

أن يقع خلاف بينهم.

Jurnal Ilmiah Al QALAM, Vol. 9, No. 17, Januari-Juni 2016 
أدي ديستري ديفيانا: نظام النقحرة من اللغة العربية إلى اللغة الإندونيسية

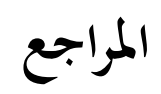

Ulul Albab: Jurnal Studi Islam sains

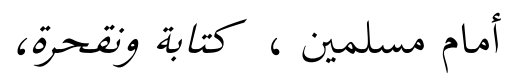
2006 ،danTeknologi vol.7 No.2

الخولي، تُحَّة ، A Dictionary of Theoritichal linguistics Englis Arabic البيروت: لبريري دو ليبان، 2008

مرتضى، مُحَّة بصري علوي، مبادئ على التجويل، مالانج: رحمتك، 2009

يامين، ناصف، المعجم المغصل في الإملاء قواعل ونصوص ، بيروت: دار المكتبة العلمية، 1992

اليسوعي، لويس معلوف، المنجد في اللغ والأعلام،بيروت: دار المشرق، 2008

Bahruddin, Adkk, Pedoman Transliterasi Arab Latin, Jakarta: Badan Litbang Agama dan Diklat Keagamaan proyek Pengkajian dan Pengembangan Lejtur pendidikan Agama, 2003

Hadariansyah, Pemikiran pemikiran teologi Dalam Sejarah pemikiran Islam, Banjarmasin: Antasari press, 2013

Jurnal Ilmiah Al QALAM, Vol. 9, No. 17, Januari-Juni 2016 


$$
\text { أدي ديستري ديفيانا: نظام النقحرة من اللغة العربية إلى اللغة الإندونيسية }
$$

Hasanah. Mamluatul,Menyingkap tabir dua kalimat syahadat,Malang: UIN Malang Press, 2008

Tim Depdiknas,Kamus Besar Bahasa Indonesia Pusat Bahasa Edisi Keempat, Jakarta: Gramedia Pusat Utama, 2008 
أدي ديستري ديفيانا: نظام النقحرة من اللغة العربية إلى اللغة الإندونيسية

Jurnal Ilmiah Al QALAM, Vol. 9, No. 17, Januari-Juni 2016 